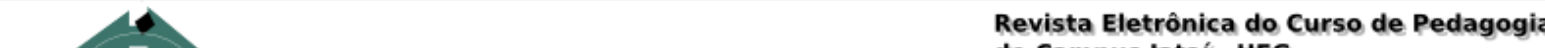 ittinerarius Reflectionis

\section{A FORMAÇÃO CONTINUADA DE PROFESSORES NA ESCOLA DE TEMPO INTEGRAL}

\author{
Ms. Iolene Mesquita Lobato \\ iolenelobato@gmail.com
}

Dra. Mercês Pietsch Cunha Mendonça

$\underline{\text { mercesmendonca@yahoo.com.br }}$

Esp.Sueli Abadia Godoi Pereira

sagodoi@hotmail.com

Curso de Educação Integral e Integrada/CEPAE/UFG

RESUMO Assim como todas as esferas da sociedade, a educação nas últimas décadas do século XX passa por profundas mudanças estruturais que perpassam por pontos relevantes como Currículo, Projeto Político Pedagógico, Formação continuada de professores. Neste estudo nossa atenção estará voltada para este último direcionando-o para a escola de tempo integral que exige do profissional da educação ações que dialoguem com outros espaços educativos, que ofereça a seus educandos uma formação completa, inteira, integral.

Palavras-chave: formação continuada, professor integral, curso de extensão.

TEACHERS' CONTINUING EDUCATION IN FULL TIME SCHOOL

ASTRACT Like all spheres of society, education in the last decades of the twentieth century is undergoing deep structural changes which involve very relevant points such as the Curriculum, the Pedagogical Political Project, and continuing teacher training. In this study, our attention will focus on the latter directing it to the full-time school, which requires from the education professional actions that dialogue with other educational spaces, offering its students a complete and utter formation. 
Keywords: continuing education; full-time teacher; extension course.

\section{INTRODUÇÃO}

Nas últimas décadas do século XX, no Brasil, inúmeros debates, reflexões e projetos são tecidos acerca da educação como um todo e de modo amplo e participativo sobre a Educação Integral. Da mesma forma, retoma-se a preocupação da formação continuada dos profissionais da educação notadamente da escola de tempo integral.

[...] a formação inicial e continuada dos professores para atender esses alunos, uma vez que não se pretende ofertar "mais do mesmo", isto é: reter os alunos nas escolas por mais tempo para desenvolver os mesmos programas até agora em execução [...] a formação continuada de professores deverá ser considerada prioritária (BRANCO, 2011, p. 247)

Nessa perspectiva, esses educadores que atuarão por mais tempo na escola deverão desenvolver ações que sejam norteadas pela organização do currículo de modo que haja ênfase na integração dos conhecimentos a partir de abordagens interdisciplinares, transdisciplinares e transversais. Educadores capazes de propor uma articulação curricular como meio do conhecimento abrangente, integral e a partir de experiências diversas, considerando que não há um único modo de ensinar e de aprender.

Neste âmbito da escola de tempo integral, Anísio Teixeira, defendia uma Escola Pública gratuita e de qualidade, adaptada às características regionais e que estabelecesse diálogo permanente com a sociedade. Para esse educador, a escola não poderia ser vista como uma instituição isolada e, ainda, deveria oferecer as mínimas condições de saúde, alimentação, acesso ao lazer, esporte e cultura. Assim, para atingir os objetivos era necessário que funcionasse em tempo integral. (TEIXEIRA, 1961)

Hoje, nos deparamos com novos idealizadores, porém com os mesmos objetivos. Moll, destaca que: 
porque entendemos que é possível ter jornada ampliada sem ter educação integral. E às vezes há um grande esforço de educação integral mesmo sem ter jornada ampliada. (MOLL, 2010, p. 2)

Essa autora enfatiza que o primeiro desafio da educação integral é a formação de professores, pois com a ampliação da jornada escolar, ou seja, mais tempo do aluno na escola, faz-se necessário capacitar, qualificar os educadores para trabalharem e realizarem ações educativas, instigantes e criativas com esses alunos. Dessa forma:

[...] a ampliação da jornada escolar, na perspectiva da Educação Integral, auxilia as instituições educacionais a repensar suas práticas e procedimentos, a construir novas organizações curriculares voltadas para concepções de aprendizagens como um conjunto de práticas e significados multirreferenciados, inter-relacionais e contextualizados, nos quais a ação educativa tenha como meta tentar compreender e modificar situações concretas do mundo. (MOLL, 2009, p. 36).

Esse novo panorama da educação - agora integral- requer desse profissional vivências e concepções diferenciadas acerca do tempo escolar, do ensino aprendizagem, na quantificação dos conteúdos, na articulação das oficinas e o conteúdo ministrado, além disso, na promoção dos espaços educativos que a cidade oferece. Assim, atuar na escola de tempo integral requer do educador ações diferenciadas, articuladas, novas formas didáticas e metodológicas de promoção do processo ensino-aprendizagem.

Mas como promover novas formas didáticas na escola de tempo integral se grande parte dos professores trabalha em instituições diferenciadas e em alguns casos nos três turnos?

Esses profissionais da educação estão capacitados para desenvolverem ações voltadas para a educação integral do sujeito?

Todas estas perguntas precisam de boas respostas, pois o princípio que rege a educação integral remete-se nos a uma dimensão qualitativa, relacionada à concepção da formação social do sujeito, assim a educação integral reside no encontro dialógico de qualidade de ensino com tempo adequado.

Assim, a proposta de educação integral vem sendo alterada na educação brasileira em diferentes momentos e a partir de diferentes propostas e experiências, mas uma característica marca todos os projetos até agora discutidos, 
a preparação dos alunos para o embate da vida, abrangendo valores éticos, sociais, familiares, profissionais dentre outros além da integração na comunidade. A educação Integral, significando uma educação escolar ampliada em suas tarefas sociais e culturais com o objetivo de reconstrução das bases sociais e indivíduos intencionalmente formados para a cooperação e a participação (CAVALIERE, 2000, p. 01).

Nessa perspectiva, a educação integral não se resume apenas na aprendizagem cognitiva, mas na ampliação da formação da criança e adolescente, contemplando as dimensões culturais, políticas e sociais. Dessa forma, ela abrangerá diversas atividades sociais que ocorrem em outros espaços fora e além da unidade escolar, estreitando assim o diálogo entre a comunidade e a escola.

Nesse âmbito, exigem-se práticas pedagógicas diferenciadas, criativas que contemplem esses outros espaços e permita construir a transversalidade entre saberes escolares e práticas comunitárias. Mas para isso o educador necessita de capacitação, formação continuada para realizar tais ações, caso contrário não atenderá a proposta de educar integralmente seus alunos.

Um projeto político pedagógico para a Educação Integral considera as múltiplas dimensões da formação humana e os diferentes contextos como a família, a escola, a comunidade próxima e a cidade, buscando favorecer aprendizagens significativas relacionadas à convivência, à participação e a autonomia (TITTON, 2008, p.72).

Dessa forma, a escola de tempo integral precisa rever e reelaborar seu Projeto, reestruturar seu currículo, (re) significar suas ações educativas. Mas para que isso aconteça o professor é peça fundamental, é ele que responde diretamente na formação da criança e adolescente.

\section{UMA HISTÓRIA}

Nos últimos anos, a formação continuada, dos educadores da rede básica de ensino, tem sido pauta de preocupação por parte dos estudiosos da área (Correia, 1989; Nóvoa, 1992, Tardif, 1999; Almeida, 2002), do Governo Federal e das Instituições de Ensino Superior- IES, dentre elas, a Universidade Federal de Goiás. 
Essa instituição tem investido, nos últimos anos, em Cursos de Extensão e de Especialização na modalidade a distância, e essa ação tem oportunizado um número significativos de professores a se qualificarem. Dentre os cursos ofertados, encontra-se o de Extensão em Educação Integral e Integrada.

Sua primeira turma iniciou em outubro de 2009, ofertando um total de 500 vagas, em dez municípios do estado de Goiás, chamados de pólos, são eles: Anápolis, Catalão, Formosa, Goianésia, Inhumas, Iporá, Mineiros, Morrinhos, Posse e Rio Verde.

Essa turma retratou de forma marcante a necessidade dos educadores se capacitarem diante dessa nova realidade da escola de tempo integral. Percebíamos que as escolas receberam do Governo Federal as diretrizes para funcionarem como a jornada ampliada, todavia se encontravam em suspense, sem saber o que fazer. Muitos gestores, educadores, secretários fizeram parte desta turma e durante as discussões no ambiente virtual de aprendizagem (AVA) relatavam as dificuldades inerentes a este nova proposta, dentre as várias, sem duvida a questão da infra-estrutura e a qualificação docente foram as mais expressivas. Este o foco do trabalho aqui proposto.

O curso teve duração de doze meses, totalizando duzentas e sessenta horas, estruturadas em dez módulos, assim denominados de: Módulo 1: Plataforma Moodle, Educação a Distância e Inclusão Social; Módulo 2: Desenvolvimento da Educação Integral no Brasil; Módulo 3: Educação Integral e Integrada: Reflexões e Apontamentos; Módulo 4: Políticas Pedagógicas; Módulo 5: Políticas Públicas; Módulo 6: Fundamentos da Educação Integral; Módulo 7: A Escola e a Cidade; Módulo 8: Educação Integral como Arranjo Educativo Local; Módulo 9: Práticas Pedagógicas Enquanto Práticas Sociais; Módulo 10: Projeto de Intervenção Pedagógica. Durante este período aconteceram dois encontros presenciais, estes foram momentos voltados para discussões e para a realização de atividades relacionadas ao conteúdo, discutidos no ambiente virtual de aprendizagem (AVA).

Com exceção do primeiro módulo que direcionou o aluno/professor à exploração do AVA e ao uso das ferramentas do Moodle, a um conhecimento sistematizado da Educação a Distancia $(\mathrm{EaD})$ no Brasil, os demais foram pautadas em discussões e reflexões sobre a educação integral, desde a sua contextualização histórica, até a possibilidade de articulá-la como um arranjo educativo local. Contemplou inúmeras temáticas, dentre elas, os saberes comunitários como instrumento pedagógico para a Educação Integral. 
O material do curso foi produzido por um consórcio de instituições a Universidade Estadual de Montes Claros/MG (UNIMONTES), Centro Federal de Tecnologia do Pará (CEFETPA), Universidade Estadual do Mato Grosso do Sul (UEMS), Universidade Federal do Paraná (UFPR) e Universidade Federal de Goiás (UFG). Cada uma dessas Instituições de Ensino Superior (IES) foi responsável pela produção de dois módulos, o que possibilitou um diálogo com outros educadores e o compartilhar das diferentes percepções e olhares em torno da temática da educação integral.

As atividades de cada módulo foram pensadas e articuladas com a realidade de cada região, paralelamente os alunos traziam suas vivencias nas discussões no AVA, e esse compartilhar de ações nos ajudou a direcionar cada módulo e que este fosse capaz de oferecer ao aluno/professor ferramentas metodológicas que os orientassem em sua prática pedagógica em sala de aula.

Sair da mesmice - utilizar somente o conteúdo didático do curso - foi uma das diretrizes encaminhadas pela Coordenação, pois se no cotidiano escolar exige-se do educador criatividade, inovação, criticidade e transformação, temos que oferecer aos nossos alunos/professores aulas elaboradas e diferenciadas, voltadas para prática pedagógica na escola de tempo integral. E ao mesmo tempo em que fossem capazes de oferecer ações para transformar a realidade. Sem dúvida foi um desafio!

Dentre as inúmeras atividades propostas, cuja perspectiva foi pautada na reflexão, questionamentos e teorização, uma merece destaque: pensada a partir do conteúdo do curso (módulo IX), seu objetivo foi instigar o aluno/professor a refletir sobre a prática pedagógica como prática social, ou seja, como a realidade do discente pode ser articulada às atividades do ensino de matemática. Como mostra a atividade a seguir:

A proposta desta atividade é ensinar a matemática de forma diferenciada e descontraída, que permita ao aprendiz lidar com situações reais e concretas. Para isso, traga exemplos (atividades, no seu cotidiano) do uso da matemática nos seguintes ambientes: no parque infantil; na cozinha; nas feiras livres; na música; no transporte; na arte; no futebol. Em seguida reflita: Como pensar a matemática voltada para a Educação integral e integrada? Por que a autora ressalta a importância de contextualizar os conteúdos trabalhos na matemática? Cite alguns exemplos para ilustrar a matemática integrada à sociedade. Poste seu relato/exemplo no fórum e comente no mínimo dois relatos apresentados pelos colegas (2009, AVA, s/n). 
As participações foram riquíssimas e mais uma vez o aluno/professor evidenciou a necessidade de práticas pedagógicas que levem o discente a pensar matematicamente. Assim, pensar uma educação matemática requer: "pensar novos tempos, espaços e modos para aprender e ensinar; levar em conta a relevância social [...]; perguntar-se quando e como conceitos matemáticos poderão ser ensinados e aprendidos” (MORAES, 2010, p.98). Em outras palavras, o ensino de matemática deve levar o aluno a questionar o mundo que o cerca e não ser pautado ao treinamento e técnicas que o reforça decorar. Como mostra o relato a seguir:

Eu fico triste quando vejo a maioria dos professores de matemática fazendo crianças decorar: "unidade, dezena, centena, tabuada..." As crianças não aprendem, apenas memorizam a posição dos números ou outros detalhes que usam como referência. Elas aprender a ver os resultados da matemática como algo pronto e acabado, não desenvolvem o raciocínio e a interpretação dos dados. E isso as formam pessoas sem muita capacidade critica e sem enxergar a dialética dos fatos. No entanto, acredito que com o tempo essas pessoas também perceberão outra forma de ensinar e poderão sim mudar. Vamos semear nossas ideias e práticas e esperar... O tempo delas chegará. Espero que em breve! (G, 33 anos)

A aluna/professor $\mathrm{G}$ defende que o ensino de matemática pode ser diferente, contudo o professor deve mudar sua forma de ensinar, utilizar outros recursos e práticas em sala de aula. Para legitimar sua argumentação, $\mathrm{G}$ compartilha uma atividade que desenvolveu com seus alunos do ensino fundamental:

Quadro 1: Hora da leitura

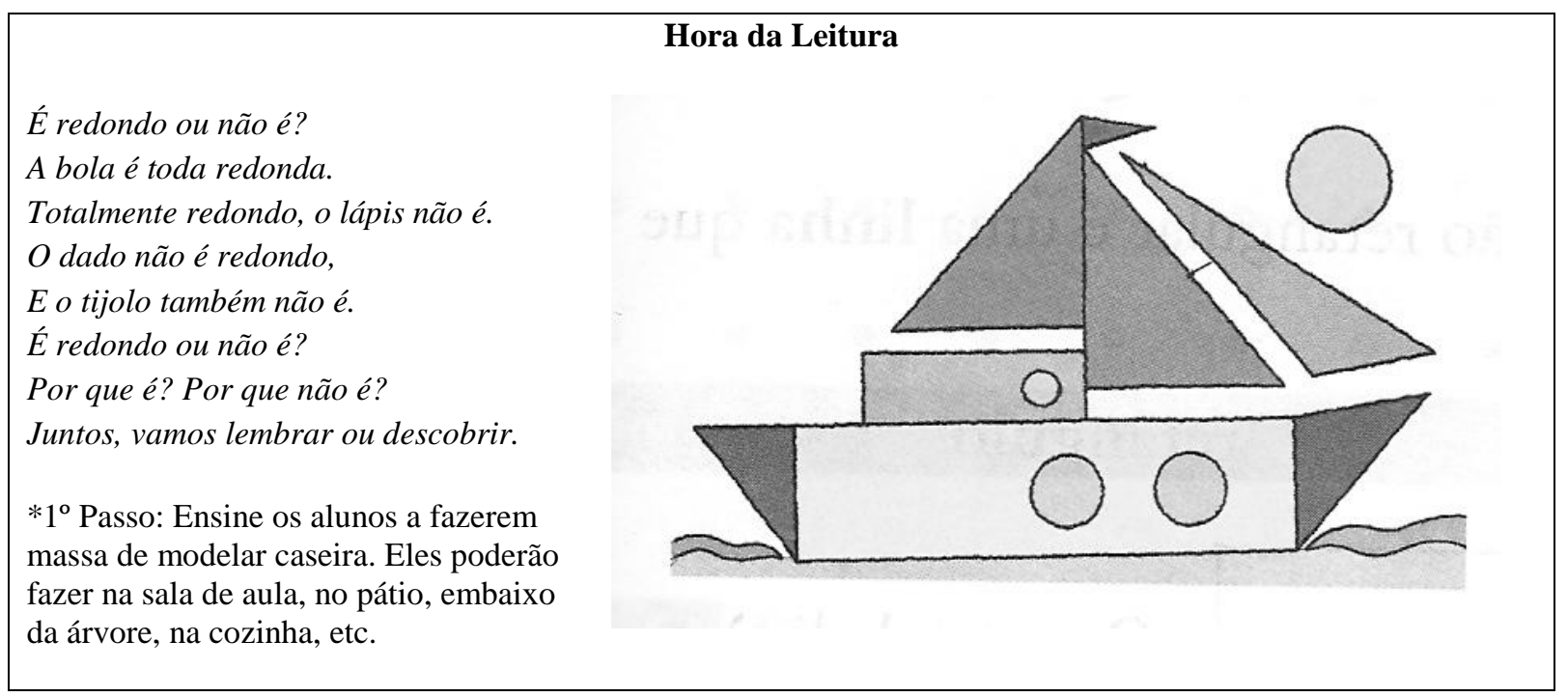




\section{Receita :}

Material:

4 xícaras de farinha de trigo,

1 xícara de sal,

1 e meia xícara de água,

1 colher de (chá) de óleo

Confecção: Numa tigela, misturar todos os ingredientes, amassar bem até ficar boa para modelar.Guardar em saco plástico ou vidro bem tampado. Atenção: Esta receita não precisa ir ao fogo. Não seca ao sol, mas você pode colocar as peças modeladas numa forma e pedir para um adulto colocar em forno brando para assar. Depois de assadas, é só pintar com tinta para artesanato ou tinta preparada por você através de nossas receitas.

Atividade: Com uma massa de modelar, reproduza estes três corpos redondos: esfera, cone e cilindro. Depois de prontos, coloque-os sobre um pedaço de papel cartão, isopor ou madeira e deixe-os endurecer um pouco. Com uma faca de madeira ou de plástico, faça um corte, de cima para baixo, em cada modelo de corpo redondo.

a) Qual das figuras abaixo você observou na região de corte da esfera? Responda indicando a posição do quadro.
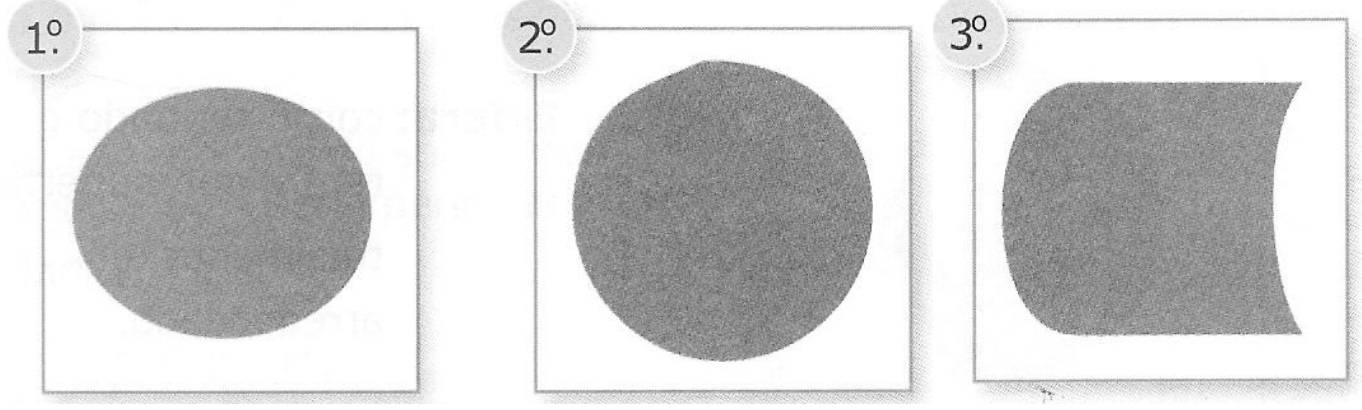

*Você sabe qual é o nome da figura encontrada na região de corte? Se souber, escrevao:

$\beta)$ Corte o cone conforme mostra a figura:

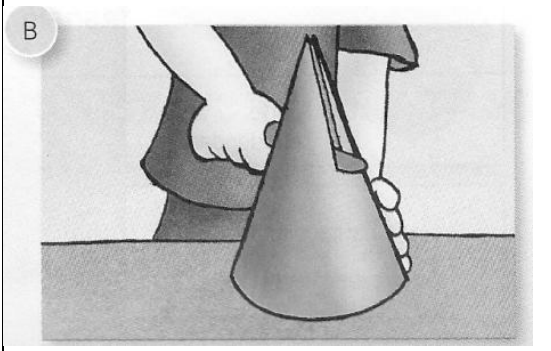

*Qual das figuras abaixo você viu na região de corte do cone? 

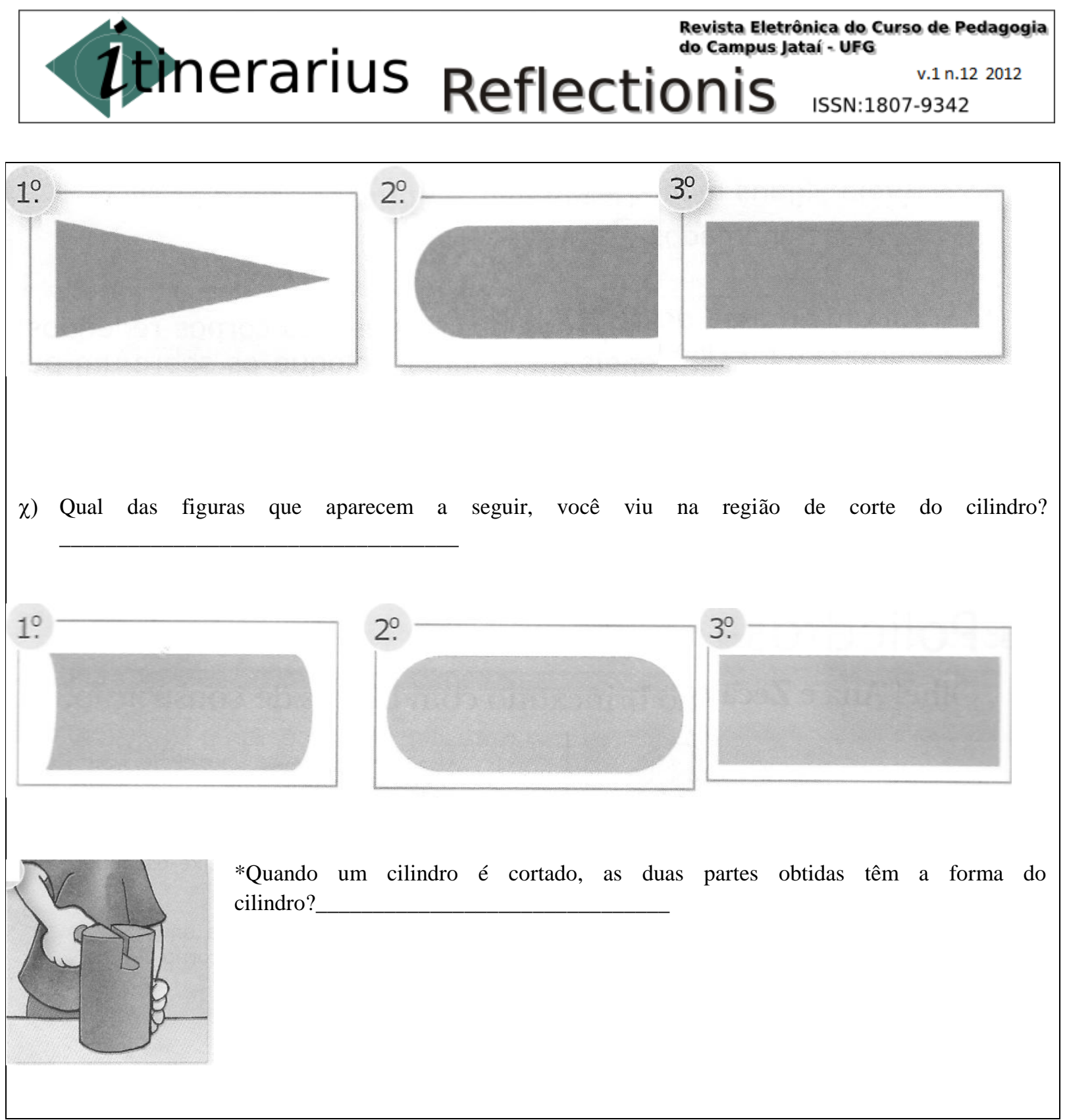

Fonte: (http://www.netds.com.br/kids/arte/massa1.htm)

Ao disponibilizar a atividade acima os colegas/professores fizeram intervenções e reforçaram a realidade do ensino de matemática em suas escolas. Enfatizaram que a matemática continua sendo ensinada de forma tradicional: o aluno decora a tabuada e realiza exercícios mecânicos. E quando são submetidos a atividades problemas não conseguem resolver. Assim, o ensino de matemática deve ser pensado e articulado aos espaços onde esses discentes freqüentam, como a escola, a casa, a rua, o clube, o cinema, como mostra a intervenção a seguir:

Concordo com você G! Ensinar matemática, principalmente, nos dias de hoje é um desafio. No âmbito escolar, a educação da matemática é vista como uma linguagem capaz de traduzir a realidade e estabelecer suas diferenças. [...] Mas, a construção desse conhecimento pelos alunos ainda está muito longe porque a prática 
desenvolvida por muitos professores ainda é tradicional, a prática deles não leva seus alunos a construírem uma aprendizagem voltada para a realidade na qual seus alunos participam. Nós, professores, temos que buscar novas estratégias para o ensino da matemática, levar para a sala de aula, métodos concretos e práticas voltadas para o cotidiano de nossas crianças (J, 33 anos).

Ela ainda sugere uma atividade:

Eu gosto muito de uma atividade que desenvolvo com meus alunos do $2^{\circ}$ ano do Ensino Fundamental I, a "Corrida das tampinhas", trabalho nessa atividade operações de adição e subtração. Distribuo uma folha para cada aluno com as mesmas perguntas $\mathrm{e}$, aleatoriamente, distribuo tampinhas de garrafas (somente de garrafas de refrigerante descartável), coloco os alunos em duplas e os mesmos têm que responder às questões sugeridas na folha, como: Quantas tampinhas você têm? Juntando você e o seu colega quantas tampinhas vocês somam? Retire 3 tampinhas do total de tampinhas suas e de seu colega, quantas sobram? Cada cor de tampinha vale certo valor (os valores das tampinhas são expostos no quadro negro), conte seus pontos. Como cada criança tem uma quantidade de tampinhas diferentes às respostas de cada dupla são diferentes ( $J$, 33 anos).

Poderíamos ilustrar inúmeras intervenções que esta possibilitou. Mas, voltemos à proposta da atividade e apresentamos a seguir duas respostas que atendem bem a perspectivas da discussão proposta:

A feira é um local riquíssimo em vários aspectos: sociais, culturais, políticos, econômicos, humanos, etc. No que se refere ao ensino de Matemática podemos trabalhar sistema monetário, porcentagem, sistema de medidas, números racionais, operações com números naturais (adição, subtração, multiplicação, divisão). É elaborar bem a atividade, direcioná-la, realizar o passeio e depois sistematizar... O resultado é significativo (M, 27 anos).

\section{Outra aluna/professora destaca:}

Realmente, uma visita à feira livre e ao supermercado ajuda muito na contextualização da aprendizagem do dinheiro brasileiro, do sistema de pesos e medidas, do valor de compra e do valor de venda, da adição, subtração, multiplicação e divisão através de situações-problemas e frações, porcentagem, lucro e etc. São atividades muito significativas. Nós, sempre que podemos, estamos promovendo-as com nossos alunos. Eles observam, perguntam, anotam, argumentam, sugerem, andam pelas bancas comparando, e na sala de aula, sistematizam o que vivenciaram orientados pela professora ( $\mathrm{V}, 21$ anos).

Sem dúvida sem a orientação didática do material do curso e de atividades diferenciadas nossos alunos/professores pouco poderiam ter contribuído e refletido sobre o ensino de matemática. 
Essa realidade apresentada nesta pesquisa reflete de forma marcante a necessidade do professor integral se capacitar para educar integralmente, com ações, atividades que despertem em seus alunos a criticidade, a reflexão e os instigue a mudar o mundo que o rodeia.

\section{REFERÊNCIAS BIBLIOGRÁFICAS}

ALMEIDA, Maria Isabel de. Os professores diante das reformas educacionais: sujeitos ou meros executores? In: Revista de Educação: Progressão continuada ou aprovação automática? São Paulo: APEOESP, 2002.

BRANCO, Veronica. A política de formação continuada de professores para a educação integral. In: MOOL, Jaqueline (Org.) Caminhos da educação integral no Brasil: direito a outros tempos e espaços educativos. Porto Alegre: Penso 2012, p.246-257.

CORREIA, José Alberto. Inovação pedagógica e formação de professores. Rio Tinto: Edições ASA, 1989.

NÓVOA, Antônio. Formação de professores e profissão docente. Os professores e a sua formação. Lisboa: Dom Quixote, 1992.

TARDIF, M. Saberes profissionais dos professores e conhecimentos universitários. Rio de Janeiro: PUC, 1999.

TITTON, Maria Beatriz Pauperio; MOREIRA Suzana Pacheco. Educação integral e integrada: reflexões e apontamentos. In: UFG/CEPAE - Universidade Federal de Goiás. Centro de Ensino e Pesquisa Aplicada à Educação. Aperfeiçoamento em educação integral e integrada/Universidade Federal de Goiás. Centro de Ensino e Pesquisa Aplicada a Educação. - Goiânia: FUNAPE/CIAR, 2010, p.63-78. 